quickly heals. Dilatation cannot therefore be recommended for routine treatment of aortic stenosis. In adults with calcific disease it is purely a palliative procedure.

Balloon dilatation of the aortic valve may, however, be useful as a bridge to an operation. Firstly, in patients in whom the operative risk is considered prohibitive because of poor left ventricular function balloon dilatation may be used before aortic valve replacement to reduce surgical mortality and morbidity. ${ }^{17}$ Secondly, we have used balloon dilatation in patients who have both critical aortic stenosis and a second medical condition requiring an urgent operation-for instance, resection of a malignancy, fixation of a hip fracture, or an operation for gastrointestinal bleeding. ${ }^{18}$ Thirdly, in patients with a low aortic valve gradient, a low cardiac output, and a small valve area balloon dilatation of the aortic valve may be used to assess the patient's ventricular response to a decreased afterload and may thus help in deciding whether to proceed to valve replacement.

MARC J LEVINE RAYMOND G MCKAY

Charles A Dana Research Institute and

Harvard-Thorndike Laboratory of Beth Israel Hospital, Department of Medicine (Cardiovascular Division), Beth Israel Hospital and Harvard Medical School, Boston, Massachusetts 02215, United States
1 Inoue $\mathrm{K}$, Owaki T, Nakamura T, Kitamura F, Miyamoto $\mathrm{N}$. Clinical application of transvenous mitral commissurotomy by a new balloon catheter. J Thorac Cardiovasc Surg 1984;87:394.

2 Lock JE, Khalilullah M, Shrivasta S, Bahl V, Keane JF. Percutaneous catheter commissurotomy in rheumatic mitral stenosis. $N$ Engl f Med 1985;313:1515-8.

3 McKay RG, Lock JE, Safian RD, et al. Balloon dilation of mitral stenosis in adult patients: postmortem and percutaneous mitral valvuloplasty studies. $7 \mathrm{Am}$ Coll Cardiol 1987;9:723-31.

4 Palacios I, Lock JE, Keane JF, Block PC. Percutaneous transvenous balloon valvotomy in a patient with severe calcific mitral stenosis. F Am Coll Cardiol 1986;7:1416-9.

5 Palacios I, Block PC. Percutaneous mitral balloon valvotomy (PMV): update of immediate results and follow-up. [Abstract.] Circulation 1988;78:11-489.

6 McKay CR, Kawanishi DT, Rahimtoola SH. Catheter balloon valvuloplasty of the mitral valve in adults using a double balloon technique. FAMA 1987;257:1753-61.
adul

7 Babic UU, Pejic P, Djurisic Z, Vucinic M, Grujicic SM. Percutaneous transarterial balloon alvuloplasty for mitral valve stenosis. Am $\mathcal{F}$ Cardiol 1986;57:1101-4.

8 Lababidi $Z$, Wu JR, Walls JT. Percutaneous balloon aortic valvuloplasty: results in 23 patients. Am F Cardiol 1984;53:194-7.

9 Rupprath G, Neuhaus KL. Percutaneous balloon valvuloplasty for aortic valve stenosis in infancy. Am $\mathcal{F}$ Cardiol 1985;55:1655-6.

10 Cribier A, Savin T, Saondi N, Rocha P, Berland J, Letac B. Percutaneous transluminal valvuloplasty of acquired aortic stenosis in elderly patients. An alternative of valve replacement? valvuloplasty of acquir.
Lancet 1986;i:63-7.

11 Cribier A, Savin T, Berland J, et al. Percutaneous transluminal balloon valvuloplasty of adult aortic stenosis: report of 92 cases. 7 Am Coll Cardiol 1987;9:381-6.

12 Leonard BM, Berman AD, Kuntz RE, et al. Follow-up of balloon aortic valvuloplasty: results in 170 cases [Abstract]. Circulation 1988;78:11-593.

13 O'Keefe JH, Jr, Vlietstra RE, Bailey KR, Holmes DR, Jr. Natural history of candidates for balloon aortic valvuloplasty. Mayo Clin Proc 1987;62:986-91.

14 Letac B, Cribier A, Konig R, Bellefleur JP. Results of percutaneous transluminal valvuloplasty in 218 adults with valvular aortic stenosis. Am f Cardiol 1986;62:598-605.

15 Block PC, Palacios IF. Clinical and hemodynamic follow-up after percutaneous aortic valvuloplasty in the elderly. Am $f$ Cardiol 1988;62:760-3.

16 Sprigings DC, Jackson G, Chambers JB, et al. Balloon dilatation of the aortic valve for inoperable aortic stènosis. BrMed f 1989;297:1007-11.

17 Block PC. Aortic valvuloplasty - a valid alternative? N Engl f Med 1988;319:169-71.

18 Levine MJ, Safian RD, Diver DJ, McKay RG. Palliation of valvular aortic stenosis by balloon valvuloplasty as pre-operative preparation for non-cardiac surgery. Am f Cardiol 1988;62: 1309-10.

\title{
Examination of the placental circulation by Doppler ultrasound
}

\section{Its place in management still to be defined}

Ultrasound techniques allow the fetus to be observed safely and directly in ways that were unimaginable 20 years ago. The most recent development is Doppler analysis of blood flow velocities, by which the two placental circulations-uteroplacental and fetoplacental - can be studied. Identifying the circulatory problems that underlie "placental insufficiency" may now be possible.

The basic measurement is the change in the frequency of ultrasound reflected from moving blood. Apart from the physical limitations of the technique there are practical problems. The first is to identify the vessel of interest and sample the flow at a known position. When the cheaper, continuous wave instruments are used the sampling depends on the observer's recognition of waveform patterns - the measurement is taken when the "right" signal is found. With concurrent imaging at least some vessels can be identified and sampled at a particular place. The new and expensive duplex colour systems enhance this capacity.

The second problem is that, although the angle at which the vessel is insonated cannot be controlled, it affects the amplitude of the signal. Absolute measurements are therefore hard to obtain. Various ratios of the maximal frequency shifts in systole and diastole are used instead, which are independent of the angle of insonation and reflect the degree to which blood flow is sustained during diastole. High diastolic flow characterises circulations with low resistances, including both placental circulations in healthy pregnancies.

The fetoplacental circulation is much easier to assess than the uteroplacental circulation. Values for normal pregnancy show a relative increase in diastolic flow maintained until 40 weeks of gestation, implying a gradual reduction in fetoplacental vascular resistance.'

Reduced or absent diastolic flow in the umbilical artery is found with some fetuses that are small for gestational age, commonly in the context of pre-eclampsia. ${ }^{2-4}$ This change should reflect an abnormally high resistance in the fetoplacental circulation, but this has not been measured and cannot be assumed. Impaired diastolic flow, however, correlates with altered structure-fewer arteries in the tertiary chorionic villi ${ }^{5}$ and function-the fetuses are usually hypoxaemic and often acidaemic. ${ }^{6}$

The best way to use this information in clinical practice has not been defined. Possible benefit has been suggested by the results of a small randomised trial: the availability of Doppler measurements of blood flow in the umbilical artery reduced the incidences of fetal distress and caesarean sections in labour.

A serious limitation is that the test shows an abnormality but not the extent of fetal reserves. Nor is the investigation a global test of fetal wellbeing: fetuses that are ill with infection, Rhesus disease, or intrinsic metabolic problems would, for example, not be expected to have abnormal readings. Some fetuses with no umbilical arterial diastolic flow are neither hypoxaemic nor acidaemic - that is, they have circulatory abnormalities but function is well maintained. But even when hypoxaemia supervenes compensatory mechanisms can be activated $^{8}$ so that delivery is not necessarily mandatory, particularly at earlier gestational ages.

In contrast, fetal heart rate patterns, controlled by the central nervous system, give a more immediate and broader, albeit incomplete, view of fetal wellbeing. The same is true of the "biophysical profile." These tests can be used to time delivery - for example, a "terminal heart rate" as defined by Visser and Huisjes ${ }^{10}$ is an absolute indication for immediate delivery unless the fetus is not viable. Doppler readings of blood velocities in the umbilical artery do not allow the need for urgent elective delivery to be assessed.

Doppler measurements are likely to become a useful 
diagnostic test of fetuses that are small for dates. The definitive studies have yet to be described, but intrauterine growth retardation with normal blood velocities in the umbilical artery will probably prove to be a largely benign condition not requiring much monitoring or intervention whereas with no diastolic flow the fetus may decompensate at any time and should be monitored accordingly. These investigations-which are not difficult to do-should therefore become a useful part of fetal assessment. But if abnormal results are taken as a cue for immediate delivery then the test is being misused and may unnecessarily acquire a bad reputation.

Because the measurement is simple it might also be used to screen unselected low risk pregnant women for placental insufficiency. Any pattern less extreme than absent diastolic flow in the umbilical artery, however, is unlikely to be worth detecting. The benefit of screening would be to identify fetuses that merit closer monitoring, not immediate intervention. Studies have still to be done to show whether this would be useful.

The second placental circulation - the uteroplacental circulation - is more complex. It is fed by four arteries (ovarian and uterine), the relative importance of each being determined by the position of the placenta. Their branches form an anastomotic network of arcuate arteries within the uterine wall. Those underlying the placental bed carry higher flows at lower resistances so there is considerable regional variation, which may be increased by focal pathology such as infarcts within the placenta. One standard artery cannot therefore be used to characterise the uteroplacental circulation, and variation caused by inadvertently sampling different arteries will be high. Moreover, visualising the relevant vessels with a duplex system is impossible without colour systems. And if the placenta is posterior then the appropriate vessels are inaccessible to examination.

Examination of the uteroplacental circulation is, therefore, more difficult and less likely to yield useful information. An initial report suggested that "high resistance" patterns in the arcuate arteries, detected as early as mid-gestation, could predict a range of fetal problems common to placental insufficiency. " Similar results have been reported by another group ${ }^{12}$ but could not be confirmed by a third, who found no differences in the uteroplacental arterial waveforms between women with pregnancy induced hypertension and matched control cases. ${ }^{13}$ The selection criteria may have been too nonspecific, focusing on maternal hypertension rather than placental insufficiency. But what is clear is that the technical problems of assessing the uteroplacental circulation are both formidable and unresolved, and the methods are a long way from application in clinical practice.

C W G REDMAN

Lecturer in Obstetric Medicine,

Nuffield Department of Obstetrics and

Gynaecology,

John Radcliffe Hospital,

Oxford OX3 9DU

1 Stuart B, Drumm J, Fitzgerald DE, Duignan NM. Fetal blood velocity waveforms in uncomplicated labour. Br F Obstet Gynaecol 1981;88:865-9.

2 Erskine RLA, Ritchie JWK. Umbilical artery blood flow characteristics in normal and growthretarded fetuses. Br f Obstet Gynaecol 1985;92:605-10.

3 Reuwer PJHM, Bruinse HW, Stoutenbeek P, Haspels AA. Doppler assessment of the fetoplacental circulation in normal and growth-retarded fetuses. Eur $\mathcal{F}$ Obstet Gynecol Reprod Biol 1984;18: 199-205.

4 Trudinger BJ, Giles WB, Cook CM, Bombardieri J, Collins L. Fetal umbilical artery flow velocity waveforms and placental resistance: clinical significance. Brf Obstet Gynaecol 1985;92:23-30.

waveforms and placental resistance: clinical significance. Br 7 Obstet Gynaecol $1985 ; 92: 23-30$.
Giles WB, Trudinger BJ, Baird PJ. Fetal umbilical artery flow velocity waveforms and placental Giles WB, Trudinger BJ, Baird PJ. Fetal umbilical artery flow velocity
resistance: pathological correlation. Br f Obstet Gynaecol 1985;92:31-8.

Nicolaides KH, Bilardo CM, Soothill PW, Campbell S. Absence of end diastolic frequencies in umbilical artery: a sign of fetal hypoxia and acidosis. Br Med f 1988;297:1026-7.

7 Trudinger BJ, Cook C, Giles WB, Connelly A, Thompson RS. Umbilical artery flow velocity waveforms in high-risk pregnancy. Randomised controlled trial. Lancet 1987; i: 188-90.

8 Smith JH, Anand KJS, Cotes PM, et al. Antenatal fetal heart rate variation in relation to the respiratory and metabolic status of the compromised human fetus. Br $\mathcal{F}$ Obstet Gynaecol 1988;95:980-9.

9 Manning FA, Baskett TF, Morrison I, Lange I. Fetal biophysical profile scoring: a prospective study in 1,184 high-risk patients. Am f Obstet Gynecol 1981;140:289-93.

10 Visser GHA, Huisjes $\mathrm{HJ}$. Diagnostic value of the unstressed antepartum cardiotocogram. $\mathrm{Br}$ Obstet Gynaecol 1979;84:321-6.

11 Campbell S, Diaz-Recasens J, Griffin DR, et al. New Doppler technique for assessing uteroplacental blood flow. Lancet 1983;i:675-7.

12 Arduini D, Rizzo G, Romanini C, Mancuso S. Utero-placental blood flow velocity waveforms as predictors of pregnancy-induced hypertension. Eur $\mathcal{J}$ Obstet Gynecol Reprod Biol 1987;26: predictors

13 Hanretty KP, Whittle MJ, Rubin PC. Doppler uteroplacental waveforms in pregnancy-induced hypertension: a reappraisal. Lancet $1988 ; \mathrm{i}: 850-2$.

\section{Anencephalic organ donors}

\section{Guidelines available from Britain and North America}

Hearts are now being transplanted into neonates with congenital cardiac malformations; hence healthy beating neonatal hearts are needed, raising profound ethical issues. Donors may be either infants born with non-cardiac malformations that will kill them within hours or days-for example, anencephaly-or normal infants who have suffered severe brain injury from which they cannot recover. Difficulties arise in diagnosing death in both categories. In anencephaly the criteria of brain stem death used in adults are inappropriate because the brain stem functions when little else does; neonates with brain injuries have a much greater facility to recover than adults, and the standard criteria of brain death may not apply.

The first neonatal cardiac transplant was performed in Britain in 1986. Because of the uncertainty that then existed about what constituted brain death in neonates the chief medical officer issued a moratorium on further transplants. He sought the advice of the conference of the medical royal colleges, which produced a report in February 1988. ${ }^{\prime}$ The moratorium was then lifted. The report of the colleges sits neatly alongside the recently published account of a meeting held in Canada in January 1987, which was convened by $\mathrm{Dr}$ Calvin Stiller to discuss the use of anencephalic donors. ${ }^{2}$

The precise need for neonatal transplantation has still to be established. The royal colleges' report considered that the cardiac malformations of a hypoplastic left heart, heterotaxy, and pulmonary atresia with a ventricular septal defect might be treated by transplantation and estimated that about 160 patients with these conditions are born each year in England and Wales. The yearly incidence of these conditions $(0.25$ deaths for every 1000 live births) is similar to that recorded for anencephalic babies in California $(0.23$ for every 1000 live births). In the United States as a whole the incidence of anencephalic babies born alive is 0.5 for every 1000 live births; the greater incidence may be explained by poorer screening programmes.

Clearly such screening programmes will influence profoundly the number of anencephalic babies who reach term. Raised maternal serum $\alpha$ fetoprotein concentrations are detectable from the seventeenth week of gestation, and the 